\title{
HISTÓRIAS DE VIDAS ESCOLARES E REAIS - RELATO DA PRODUÇÃO DE UM VÍDEO SOBRE O PROCESSO DE ALFABETIZAÇÃO DOS ALUNOS
}

\author{
Fernanda Lino (Mestranda em Educação - PPGE/UFSC) - lino.nanda@gmail.com \\ Sílvio da Costa Pereira (Jornalista e Mestre em Educação) - costapereira@floripa.com.br \\ Viviane Gonçalves Lapa Raulino (Pedagoga) - vivianeglr@hotmail.com
}

RESUMO: Este artigo apresenta um relato crítico da experiência de produção de um vídeo com alunos da turma de alfabetização de jovens e adultos. A produção se deu em um contexto de estímulo ao uso das ferramentas informatizadas e do consumo crítico das mídias, e buscou recuperar a história de vida que levou os alunos a parar e voltar, anos depois, a estudar.

Palavras-chave: educação de jovens e adultos; mídia-educação; alfabetização.

\section{REAL AND SCHOOL LIFE HISTORIES - VIDEO PRODUCTION ACCOUNT ABOUT A STUDENTS LITERACY PROCESS}

Abstract: This paper presents a critic account about a vídeo production experience with youth and adult literacy students group. The production occured in a computacional tools usage and media critical consumption stimulus context, and wished recover the life history that push students to stop and resume to study, years later.

Keywords: youth and adult education; media-education; literacy.

\section{Introdução:}

O projeto que relatamos neste artigo nasceu do desejo comum entre a professora da turma de Alfabetização (Jovens e Adultos - Primeiro Ciclo) e a professora responsável pela Sala Informatizada, em trabalhar com a turma de maneira significativa, com projetos específicos, de modo a tornar o ambiente informatizado crítico, prazeroso, de aprendizagem e muitas trocas. A turma, com todas suas diferenças, semelhanças e singularidades, estudava no Núcleo Central da Educação de Jovens e Adultos, mantido pela Secretaria Municipal de Educação de Florianópolis no centro da cidade. Neste espaço são oferecidos dois segmentos do curso de Educação de Jovens e Adultos, sendo o primeiro correspondente à Alfabetização ( $1^{\mathrm{a}}$ a $4^{\mathrm{a}}$ série), e o segundo ao Ensino Fundamental ( $5^{\mathrm{a}}$ a $8^{\mathrm{a}}$ série). O Núcleo atende alunos a partir de quinze anos de idade. $\mathrm{O}$ curso de Educação de Jovens e Adultos é planejado e estruturado através de pesquisas, em grupos de poucos alunos. Diferente do que existe nas escolas de Ensino Fundamental, estruturadas de acordo com currículos e disciplinas, é nas pesquisas que reside o princípio educativo do EJA. Nessa proposta, o processo da pesquisa se inicia a partir dos interesses dos estudantes com a formulação de perguntas/problemáticas, que estão ligadas às suas necessidades e curiosidades.

A idéia inicial era trabalhar com um projeto de vídeo de animação, pois a professora da Sala Informatizada havia participado de um curso sobre animação e proposto tal atividade para a professora da turma. No entanto foi percebido que a maior parte da turma se mostrava ansiosa para aprender a mexer no computador, pois muitos nunca haviam tido contato com estes equipamentos. Por outro lado alguns - em especial os de mais idade - afirmavam não gostar muito de freqüentar a sala informatizada.

A maioria dos alunos esperava ter um curso de computação. Por isso elaboramos uma oficina de noções básicas sobre o uso do computador, explicando a utilidade de todos aqueles objetos que estavam lá. Depois, com a ajuda de um projetor, mostramos como se fazia o uso do mouse e passamos para o editor de textos, no qual os alunos experimentaram escrever, embora muitos ainda estivessem no início do processo de 
alfabetização e letramento. Pouco a pouco, na medida em que era sentido o avanço de cada um, os alunos iam sendo convidados a participar de atividades em sites educativos. A maioria demonstrou gostar muito dessas atividades. Nesse período foi realizado um projeto sobre alimentação. O trabalho foi esboçado na sala de aula e finalizado na Sala Informatizada, onde foram realizadas algumas pesquisas de imagens para a elaboração de um folder informativo com dicas para uma alimentação saudável. Junto dessas atividades sempre se buscava discutir a importância dos meios de comunicação, procurando entender como eles estavam presentes na vida dos alunos, e o que os alunos pensavam a respeito das mídias.

Durante o primeiro semestre, os alunos da EJA estavam participando de várias atividades, tais como assistir peças de teatro, filmes ou espetáculos. Alguns alunos da turma de alfabetização afirmavam não gostar dessas saídas, pois isso tirava o tempo de sala de aula, em que a professora os ensinava a ler e a escrever, necessidade e razão pelas quais estavam ali. Essa fala, de alguns alunos alertou para a ânsia que alguns possuíam em relação à alfabetização, e também para a necessidade de repensarmos nossa ação em relação aos meios de comunicação.

Ainda no início do primeiro semestre, por meio de muitas conversas em sala de aula, de troca e riqueza de relatos, surgiu a idéia de escrever um livro sobre a história de cada um dos alunos. Ao final do projeto sobre a alimentação foi realizada reflexão e avaliação de tudo que já havia sido feito. A professora da turma relembrou a primeira semana de aula, na qual ocorreu a apresentação dos alunos, com entrevistas. Nesse dia cada estudante foi um 'jornalista': conversou com um colega, para depois apresentá-lo e contar um pouco de sua história ao grupo. A partir desta apresentação a professora observou que muitas pessoas falavam que "minha história dá um livro”, e percebeu que muito poderia ser trabalhado. Discutiu-se então a possibilidade de elaborar um livro. Entretanto um aluno propôs que se fizesse um filme sobre a história da turma, com o objetivo de que o mesmo fosse exibido para crianças e adolescentes nas escolas, com o intuito de alertá-los sobre a importância do estudo. A idéia foi aceita por todos, embora alguns ressaltassem que tentariam escrever o livro, mas não queriam participar do filme. Essa resistência, como se percebeu ao longo do processo, foi diminuindo, e todos aqueles que inicialmente se negaram a participar apareceram no vídeo realizado. Isso foi muito positivo. Neste período ficou decidido que o projeto seria realizado usando estas duas mídias, o livro e o vídeo, sendo que a participação em ambos era voluntária para os alunos.

\section{O processo:}

Tanto a professora da turma como a professora da sala informatizada se identificam muito com as concepções teórico-metodológicas de Paulo Freire, acreditando que o diálogo e a comunicação são fundamentais no processo de construção do conhecimento. Para Freire, uma aprendizagem significativa que promova a superação de desigualdades sociais, e que promova a construção da autonomia e da conscientização crítica dos sujeitos, deve se fundamentar numa relação dialógica entre conhecimento, educadores e educandos, pois "não é no silêncio que os homens se fazem, mas na palavra, no trabalho, na ação-reflexão" (FREIRE, p. 78).

Considerando que as possibilidades de comunicação e diálogo atualmente tem se ampliado significativamente - em especial devido ao crescente consumo de tecnologias digitais pela população, o que inclui os alunos - tinha-se noção da importância de se trabalhar educativamente com, sobre e através dos meios de comunicação para contribuir no processo de alfabetização e construção da autonomia e consciência crítica dos alunos. Mas ainda não se tinha bem claro como articular a alfabetização com o 
trabalho com mídias.

Com a idéia do documentário, proposta pelos próprios alunos, percebeu-se que era necessário buscar parcerias, já que as professoras não tinham experiência do trabalho com vídeo. Este apoio foi obtido junto a um jornalista, que além de explicar às professoras como se dava o processo de criação de um documentário - planejar e executar uma sinopse, uma pesquisa sobre o tema, um pré-roteiro, organizar os elementos necessários para as gravações tais como agendar as entrevistas ou conseguir as câmeras, realizar as filmagens, decupar todo o material obtido, elaborar o roteiro, editar e resolver detalhes finais tais como fazer cartazes ou capas e planejar as exibições - se propôs a ministrar uma oficina de vídeo para os alunos.

O jornalista propôs que se buscasse planejar as atividades a partir da noção de aspectos-chave propostos por Bazalgette (1992). De acordo com a autora, é importante que as atividades mídia-educativas abordem a agência, as categorias, as tecnologias, as linguagens, a audiência e a representação dos meios de comunicação, de forma entrelaçada e não-sequencial.

Depois de se ter a noção de como seriam feitos o documentário e o livro com a turma, realizou-se a construção da sinopse em sala de aula. Logo em seguida foi iniciado o processo de escritura do livro, e do pré-roteiro para o documentário. Ficou decidido que tanto o livro como o documentário iriam abranger três questões: identificação (nome, local de nascimento, idade, etc), por que parou de estudar, e por que voltou a estudar. Este seria o eixo do projeto em torno do qual as histórias de vidas iriam sendo reveladas.

Como a temática do analfabetismo estava presente nas discussões, realizamos pesquisas sobre índices de analfabetismo e evasão escolar no Brasil, e com auxílio de gráficos e mapas a turma percebeu que a nossa cidade e o nosso estado possuem uma das menores taxas de analfabetismo do país. Mesmo assim alguns alunos disseram não enxergar a questão dessa maneira, pois para eles o analfabetismo estava em todo o Brasil, de maneira abrangente. Na visão desses alunos, Santa Catarina pode até ter menos analfabetos, mais mesmo assim ainda tem muitos. Junto a esse debate a professora da turma trabalhou sobre os Estados brasileiros, contextualizando a origem dos alunos, suas culturas e tradições, pois a maior parte dos alunos não era nascida em Florianópolis.

Junto a isso foi exibido o documentário Histórias de um Brasil Alfabetizado (acervo da TV Escola), que apresenta experiências de alfabetização de adultos em quatro cidades brasileiras. A turma gostou bastante desse vídeo, e alguns alunos relataram se identificar com algumas pessoas retratadas.

Depois de reflexões e debates a turma participou, em 10 de junho, do primeiro dia de uma oficina de produção de vídeo, que foi ministrada pelo jornalista e por uma professora multiplicadora do Núcleo de Tecnologia Educacional da Prefeitura Municipal $^{1}$. O objetivo da oficina foi instrumentalizar os alunos para que eles mesmos pudessem filmar o documentário, assim como participar de todo o processo de criação, fornecendo elementos para uma alfabetização digital e midiática. Além disso se queria mostrar que a comunicação humana não é somente - ou preferencialmente - feita por textos escritos ou orais, ressaltando a importância de 'ler' e compreender os 'textos' audiovisuais. Neste sentido, Silverstone (2003, p. 58) já nos alertava para que:

“A cidadania do século XXI requer um grau de conhecimento que até agora poucos de nós têm. Requer do indivíduo que saiba ler os produtos de mídia e que seja capaz de questionar suas estratégias. Isso envolveria capacidades que vão além do que foi 
considerado alfabetização em massa na época da mídia impressa."

A oficina foi dividida em dois encontros. No primeiro encontro foram abordados alguns elementos técnicos a respeito da filmagem como enquadramento, iluminação, manuseio da câmera, uso da câmera no tripé e nas mãos, planos, áudio e movimentos de câmera. Foi ressaltado que as gravações poderiam ser refeitas quantas vezes fosse necessário, e que por isso eles não deveriam ter medo de errar: errou, grava de novo. Abordou-se também que ler e escrever são duas coisas muito ligadas, e que geralmente quem aprende um também aprende o outro. Mas que não são só letras que podem ser 'lidas', ou seja, compreendidas como tendo algum sentido. Sons e imagens também trazem significados. Como exemplos, foram lembradas a música do caminhão de gás, a entrada do jornal nacional o hino nacional. Da mesma forma há uma série de imagens que tem significados conhecidos. Uma série de listas pintadas no asfalto indica uma faixa de pedestres, a posição dos ponteiros do relógio mostra as horas e uma placa com um desenho indica o local de parada de ônibus. Mas uma pessoa que vier de outro país, ou que não conheça esses sons e imagens, não vai entender o que eles significam. Isso mostra que eles são lidos, mesmo que a pessoa não se dê conta disso.

E quando se vê que é possível ler esses sons e imagens, descobre-se que também é possível escrevê-los: criar sons ou imagens que tenham significado para outras pessoas. Na TV, sabemos diferenciar uma novela/filme (ficção) de um jornal (real). Como? O que os torna diferentes? Porque em geral as pessoas acreditam no que o jornal diz e não levam a sério o que a novela/filme conta? Um dos motivos é que há uma série de marcas que constroem essa diferença, tais como a notícia ser apresentada por alguém com aspecto sério, vestido formalmente, em programas ditos jornalísticos, e usando sempre as mesmas técnicas (entrevista, passagem e off, no caso do telejornalismo). Mostrou-se aos alunos que para fazer um documentário é importante conhecer outros documentários já feitos, para ver quais são as convenções usadas para dar credibilidade, ou para facilitar a compreensão do que se irá contar. Com auxílio de um projetor multimídia, todos esses conceitos foram ilustrados através de trechos de vídeo, o que tornou a oficina bastante dinâmica. Alguns alunos, neste primeiro momento, provavelmente os mais cansados do trabalho, ou aqueles que já haviam afirmado que não participariam das filmagens e que estas atividades tiravam o tempo da 'aula', estavam meio sonolentos e demonstraram certo desinteresse. A atividade ocupou a primeira metade da noite (cerca de uma hora e meia).

Depois do intervalo os alunos foram divididos em grupos e colocaram a mão da massa, filmando e sendo filmados. Neste momento os alunos que pareciam desanimados passaram a ficar mais empolgados com o projeto, embora alguns continuassem afirmando que não participariam das filmagens. O interessante é que nesta mesma noite alguns já mudaram de idéia e começaram a relatar suas histórias. Nos últimos momentos desse primeiro foram exibidas e discutidas - a partir dos conceitos levantados na primeira parte da oficina - algumas gravações feitas nesse dia.

Durante a semana seguinte a turma realizou, em sala de aula, um roteiro de entrevista para professores e funcionários do Núcleo. O objetivo era no próximo encontro realizar mais um exercício de filmagem. Também nessa semana a professora da Sala Informatizada e a professora da turma deram aos alunos algumas noções de edição, ao exibir um vídeo com todas as fotos da turma desde o início do ano, com música. Os alunos gostaram muito desse trabalho, e foi possível refletir rapidamente a respeito da maneira como as imagens são montadas, em novelas, telejornais e outros programas.

No segundo dia de oficina de vídeo (23 de junho), foi apresentado um vídeo 
editado a partir de imagens gravadas no primeiro dia da oficina, ressaltando alguns detalhes e conceitos já discutidos, e ressaltando também a maneira como se editam as imagens. Depois, os alunos passaram para a gravação das entrevistas, conforme o roteiro elaborado na semana anterior, com professores, funcionários e até mesmo com outros colegas do Núcleo. Bem mais familiarizados com as câmeras, alguns alunos mostraram-se bem empolgados tanto para filmar como para serem filmados. Alguns poucos ainda mantinham resistência em serem filmados, mas era nítido que pouco a pouco a turma ia ficando mais envolvida com o projeto do documentário e perdendo a timidez diante das câmeras. Neste momento do projeto, alguns alunos também já estavam impacientes e questionavam “afinal quando vamos filmar de verdade?”, ansiosos pelo dia de gravação de seus relatos.

O passo seguinte foi os alunos passarem para a elaboração do pré-roteiro do documentário. Como a escritura do livro estava acontecendo em paralelo e alguns alunos já estavam adiantados na escrita, a turma elaborou conjuntamente um pré-roteiro de perguntas para serem respondidas nas gravações para o documentário. As perguntas eram, basicamente: Qual seu nome? Qual sua idade? Onde nasceu? Até que série estudou? Porque parou de estudar? Ou, quais os motivos para não ter estudado? O que motivou a voltar os estudos? Você acha importante estudar? Quais os seus sonhos?

O início das filmagens se deu, entretanto, apenas no início do segundo semestre, nos ambientes do Núcleo de EJA, no período noturno, conforme acertado com a turma. Foram combinados os dias e os entrevistados, entretanto este agendamento sofreu certos imprevistos e foi modificado ao longo das gravações.

A primeira dificuldade técnica foi a escolha da câmera, pois não havia filmadora disponível. Conscientes de que teriam de que teriam de fazer o vídeo com os equipamentos disponíveis, e não com os ideais, as professoras decidiram filmar com suas próprias máquinas fotográficas digitais. Nesse período havia uma certa pressa em concluir o vídeo até o início de setembro, para exibição do mesmo na Semana Nacional de Alfabetização, promovida pela Prefeitura.

Em meio às filmagens com a primeira máquina, estragou o cartão de memória, e com isso perderam-se várias entrevistas. Nas gravações seguintes percebeu-se que o áudio estava com baixa qualidade, mas foi decidido continuar as gravações assim mesmo pois não se tinha equipamentos que pudessem resolver esse problema causado pela fala baixa de algumas pessoas ou pelo ruído que vinha da rua e dos corredores. Depois do problema com a primeira máquina, obteve-se emprestada uma máquina que possuía qualidade de imagem e de áudio superior as dos primeiros registros. No entanto, em um dos dias no qual no qual não houve tempo para baixar as imagens no próprio Núcleo, o cartão foi formatado acidentalmente antes das gravações serem transferidas para o computador. Perdeu-se assim mais gravações, o que levou à necessidade de mais regravações e improvisos. Nestas ocasiões alguns alunos relataram estar cansados do projeto. Houve também dificuldade com a iluminação, pois as gravações eram todas feitas no período noturno. As imagens melhoraram a partir do empréstimo de um refletor, que passou a ser usado em todas as gravações. Alguns alunos ficaram desanimados em função da perda de suas entrevistas, e no momento da produção comentavam que a gravação perdida tinha ficado melhor que a segunda versão. Outros não gostaram da idéia de ter que falar tudo novamente.

Durante todo este processo, procurou-se sempre ressaltar para a turma que, se alguma coisa não desse certo, ou os alunos não gostassem ou não se sentissem seguros, nós poderíamos refazer, e que o documentário que seria exibido no evento da Semana de Alfabetização seria um resultado parcial do projeto, que poderia ser modificado de acordo com o interesse da turma. 
Também chegou-se à conclusão de que, naquele momento, não seria possível que os alunos participassem do processo de edição do documentário, por duas razões principais. A primeira é que ensinar os alunos, principalmente nesta etapa de alfabetização, a usar um programa de edição de vídeo demandaria tempo. A segunda era a dificuldade em obter um micro que pudesse ser usado para fazer a edição com os alunos, já que todos da sala informatizada usavam o sistema operacional Linux e não se tinha nenhum editor de vídeo que estivesse em português, fosse de aprendizagem e uso simples, e permitisse editar tanto as trilhas de vídeo quanto de áudio. Inicialmente pretendia-se usar o Kino - um dos programas mais populares de captura e edição básica de vídeo em Linux - mas esta opção foi descartada pela impossibilidade de inclusão/edição de trilhas de áudio.

Iniciou-se a edição do vídeo usando o MovieMaker (da Microsoft, em sistema operacional Windows), a partir do roteiro proposto pelos alunos, em computadores próprios (não na escola). Entretanto surgiram problemas por causa da pouca memória instalada e pelo fato deste equipamento usar um processador já antigo e lento. Isso fazia com que o micro travasse ou o processo de edição ficasse lento demais. Percebeu-se então que para a edição de áudio e vídeo é fundamental utilizar uma máquina com pelo menos 1 gigabyte de memória RAM e um bom espaço em disco para gravar os arquivos. Neste meio tempo, foi exibida para os alunos uma versão parcial do documentário, faltando ainda alguns relatos, músicas, efeitos, créditos e detalhes de edição. Os alunos pareceram satisfeitos com este resultado parcial, exceto algumas críticas relacionadas à perda de relatos e a qualidade do áudio de algumas gravações.

Com a inserção das últimas entrevistas ficou impossível trabalhar com o micro no qual havia sido iniciado o processo. Além da lentidão e travamentos, o mesmo não possuía gravador de DVD. Os arquivos foram levados, via pendrive, para o computador do jornalista, no qual assistiu-se ao que já havia sido editado, sendo anotamos alguns detalhes para corrigir. Um dos problemas notados foi a perda de sincronia entre imagem e áudio de algumas entrevistas. Além disso, em algumas gravações, o áudio estava muito baixo, quase inaudível. Para corrigir o volume foi amplificado um pouco o áudio das entrevistas mais baixas, usando o editor de áudio Audacity ${ }^{2}$. O problema de perda de sincronia foi resolvido através do Linux (Ubuntu), convertendo os arquivos ${ }^{3}$ de video de AVI (formato original gravado pelas máquinas) para MPEG. Foram tentadas quatro opções: VCD (qualidade baixa, para computadores), SVCD (qualidade média, para TV e computadores), DVD (qualidade alta, para TV e projeções) e DV (vídeo digital, alta qualidade). Usou-se o SVCD porque foi a única opção que resolveu o problema (recuperou a sincronia entre áudio e vídeo), embora talvez se tenha perdido um pouco da qualidade das imagens. Mesmo assim ainda restaram três trechos de entrevistas nos quais esta operação de conversão não recuperou a sincronia.

A edição foi então refeita em um programa de edição profissional de vídeo ${ }^{4}$, na mesma seqüência em que já havia sido feita em MovieMaker, com apenas alguns ajustes. Letreiros e legendas foram recolocados e, sem seguida, o vídeo foi renderizado (a seqüência de pequenos trechos foi convertida em um arquivo único de vídeo) para AVI. Este arquivo foi usado para gravar o DVD. Uma segunda renderização foi feita, desta vez para MPEG, para gerar o arquivo de vídeo que foi utilizado para apresentar o documentário direto em computadores.

A primeira exibição do documentário foi feita dia 6 de setembro, junto a várias outras atividades, durante a Semana de Alfabetização, promovida pela Prefeitura Municipal. Nem todos os alunos que participam do documentário estavam presentes, por isso foi feita outra exibição no próprio núcleo da EJA. Em conversa informal, após a exibição, os alunos demonstraram ter gostado bastante, tanto de sua participação quanto 
da dos colegas. Alguns alunos comentaram que só não gostaram muito do som de algumas partes do vídeo. Áudio baixo e dessincronizado do vídeo foram as principais reclamações. Outros pediram uma cópia, pois queriam mostrar o trabalho para os familiares. Alguns alunos que não haviam assistido ao vídeo questionaram por que entraram na edição algumas cenas feitas na oficina de vídeo, e não na gravação que foi 'pra valer', fato que ocorreu em função da perda de algumas gravações.

Quanto ao processo de escritura do livro, os alunos não demonstraram muitas dificuldades de digitação e de uso do editor de texto, pois já tinham tido outras experiências com estas ferramentas. A primeira versão da história de vida foi feita no caderno, e após discussão e correção os alunos passavam para a digitação. Houve, entretanto, outros problemas. Perdia-se muito tempo para iniciar os computadores e alguns depois se desligavam sozinhos. Houve por isso perda de arquivos de alunos, que não foram recuperados. Houve o caso de uma aluna que por causa de freqüentes quedas de energia, e outros problemas técnicos, chegou a perder seu relato três vezes. Esses problemas técnicos desanimaram um pouco alguns alunos nesta etapa de digitação. Em função disso a professora da turma ajudou um pouco junto àqueles que têm mais dificuldade na escrita. O processo de produção do livro não havia sido concluído até a data de fechamento deste artigo.

A turma também realizou uma atividade de auto-retrato, onde desenharam a si mesmos junto a outras pessoas ou coisas que julgavam importantes para sua história. Os alunos também se desenharam em uma etapa significativa de suas vidas. Estes desenhos e auto-retratos estão sendo digitalizado para que venham a fazer parte do livro, dentro do relato de cada aluno. A idéia inicial era usar essas imagens também no documentário, junto com fotos da infância e da adolescência deles. No entanto apenas uma aluna levou fotografias para a sala de aula. Os demais afirmaram que não tinham tirado fotos na infância, já que a fotografia não era tão popular em seus contextos, ou já tinham se perdido pela vida afora.

\section{Conclusões:}

Este processo revelou a importância de um trabalho interdisciplinar. Se faltava às professoras um maior embasamento sobre a importância em poder ler e escrever através de múltiplas mídias, faltava ao jornalista conhecimento sobre o trabalho de alfabetização. Por isso a colaboração do agente externo à escola não se resumiu a ajudar a resolver apenas problemas técnicos. Havia muitas dúvidas sobre se era importante trabalhar com vídeo, áudio ou computadores junto a alunos de alfabetização. Havia dúvidas sobre o que trabalhar, de que forma trabalhar, até porque as próprias professoras foram alfabetizadas e educadas prioritariamente com o texto lido/escrito. Havia também uma grande ânsia em resolver todas as dúvidas, em fazer os alunos compreenderem a importância do vídeo ou do uso do computador, em se interessarem por isso.

A possibilidade de contar com o apoio de dois profissionais recém-egressos de uma pós-graduação voltada para a mídia-educação permitiu ver que esse primeiro trabalho era apenas uma pequena parte de um longo processo. Um processo de aprendizagem tanto para os alunos quanto para os professores. Do lado dos alunos, eles estavam aprendendo que ler e escrever não é possível apenas com impressos. E ao aprender a se expressar através do vídeo e de outras mídias, podem também compreender que em todos os textos há uma voz que fala, e que essa voz fala a partir de um ponto de vista, que representa uma idéia, não uma verdade universal. O trabalho em grupo também permite que eles possam ver que os 'textos' das mídias são, muitas vezes, feitos coletivamente, e que as idéias veiculadas são discutidas e selecionadas por essas pessoas que fizeram os textos, o vídeo, a revista, o jornal, o documentário. E é um 
processo também para as professoras, que estão aprendendo a lidar com outras mídias, que estão aprendendo conceitos sobre comunicação, a ligar essas noções com tudo o que já sabem sobre Educação, aprendendo noções técnicas mas também aprendendo que não é a tecnologia que deve estar em primeiro plano e sim os objetivos pedagógicos, entre outras importantes noções. Neste sentido os aspectos-chave propostos por Bazalgette ajudam a evitar que os professores usem o senso comum ou seus próprios conhecimentos gerais para dar rumo ao trabalho, o que poderia levar a abordagens descontextualizadas ou focadas em uma única questão. E é um processo de aprendizagem também para o profissional de comunicação, que aprende a trabalhar com alunos, com alfabetização, com problemas diversos da prática comunicacional diária, e voltados ao campo da Educação.

Era claro para o grupo, desde o início, que esse trabalho não iria sair o melhor vídeo do mundo, concorrendo a Cannes. Ele seria uma história, contada com recursos que até então pouco se usava: áudio e vídeo. Poderia ter sido contado através da escrita como alias também foi feito, em paralelo ao vídeo - ou de outras mídias: o importante é ver que ambas as formas de contar a história (o vídeo e o livro) se complementam. Que é possível usar outras mídias para também ajudar a contar as histórias (fotografias, mapas, etc.). Mas nunca perder de vista que, pedagogicamente, o processo é fundamental, e o produto importante para que os alunos vejam o que fizeram, pois isso os estimulará. Além disso, no caso específico, o relato dos alunos pode ser muito importante para quem parou de estudar. Apesar de toda essa importância, é interessante ver que esse produto pode ser complementado, alongado, melhorado nos anos seguintes. O fim é apenas um ponto de parada provisório, que serve para olhar para trás, para avaliar o que foi feito, para vislumbrar novos caminhos a partir de onde se chegou. Mas que esse fim provisório é parte do caminho, e que por isso o processo de aprendizagem é o foco do trabalho. Muito mais do que ter um lindo vídeo, bem apresentado, mas feito por especialistas, é melhor ter um vídeo com problemas, mas que tenha sido feito e compreendido pelos alunos, pois nesse segundo caso terá havido um processo educativo significativo. Caso especialistas façam o vídeo para os alunos, o que terá ocorrido é um espetáculo, um show, muito bonito mas pedagogicamente fraco para o processo educacional desses alfabetizandos.

$\mathrm{Na}$ avaliação dos alunos, o trabalho foi satisfatório, apesar dos problemas já relatados. Muitos comentaram sobre a perda da timidez e um ganho na auto-estima, na confiança em si mesmos. Observamos que depois do projeto os alunos passaram a participar mais alegremente de atividades fora da sala de aula, como saídas a espetáculos, feiras e filmes. Se no início havia muita vergonha, além de acharem perda de tempo, a maioria dos alunos relatou que agora encaram a máquina fotográfica, a filmadora, enfim os meios de comunicação e as tecnologias, de outra maneira, com menos medo e com o olhar mais crítico. Alguns alunos da turma que participaram do documentário também atuaram em uma apresentação de teatro, intitulada Gaia e realizada na Semana de Alfabetização. Foi um fato marcante para os alunos e professoras, pois ficou claro que ali haviam sido superados muitos medos, dificuldades, vergonha e incertezas. Os três alunos da turma de Alfabetização que participaram da peça afirmaram que foi a primeira vez que participavam de uma peça de teatro, e que o projeto do documentário certamente lhes deu coragem para isso.

Neste sentido, foi observável que houve um salto de qualidade na comunicação interpessoal da maioria dos alunos. Ao relatar suas histórias tanto oralmente como em texto escrito, os alunos passaram a se ver como sujeitos da própria história. Puderam também reconhecer-se como membros de uma família ou de grupos sociais dentro dos quais vivem ou viveram, percebendo diferentes modelos de família e costumes, o que 
possibilitou a eles perceber também a grande diversidade cultural que nos cerca.

Por meio dos relatos também foi possível refletir sobre alguns aspectos do analfabetismo, bem como do campo educacional brasileiro. Muitos dos relatos falavam do não ingresso ou do abandono da escola em função do trabalho, alguns ainda na infância, para ajudar a família. Houve também muitos relatos sobre a violência das professoras. Por outro lado, o motivo mais comumente apontado para o retorno aos estudos foi aprender a ler e escrever. A grande maioria disse que deseja ter autonomia para se locomover, pegar ônibus, ler documentos, placas, etc.

Observamos também que são muitos os obstáculos que o aluno adulto enfrenta para voltar a estudar, especialmente aqueles que trabalham durante o dia, que estão muitos anos fora da escola (ou nunca chegaram a freqüentar a escola, como é o caso de um dos aluno), e que moram em regiões muito afastadas do centro da cidade. Por outro lado, fica evidente nos relatos o desejo e a necessidade de voltar a estudar, de aprender a ler e escrever, demonstrando uma grande e admirável força de vontade para superar todas as dificuldades impostas pela vida.

\section{Notas:}

${ }^{1}$ Ambos haviam recém-defendido suas dissertações de mestrado em Educação (PPGE/UFSC) com temática voltada à Mídia-Educação no ambiente escolar.

${ }^{2}$ Software livre que roda em Windows, Linux ou Mac.

${ }^{3}$ Usamos o comando "FFMPEG -i arquivo.avi -target NTSC-SVCD arquivo.mpg"

${ }^{4}$ Adobe Premiere

\section{Referências Bibliográficas:}

BAZALGETTE, Cary. Key aspects of Media Education. In Media Education, an introduction. BFI, London, 1992. p199-219.

FREIRE, Paulo. Pedagogia do Oprimido. Rio de Janeiro: Paz e Terra, 1987.

SILVERSTONE, Roger. Inventar o quinto poder. Entrevista à Ubiratan Muarrek.

Revista Carta Capital. São Paulo, edição 227, 12/02/2003, p. 58. 